\title{
JUVENTUDES NA EDUCAÇÃO DE JOVENS E ADULTOS: CONTRADIÇÕES ENTRE SUAS CONQUISTAS COMO SUJEITOS DE DIREITOS E OS SILENCIAMENTOS NOS ESPAÇOS ESCOLARES
}

\begin{tabular}{c} 
E. O. Souza, R. Reis \\
Universidade Federal de Alagoas \\
manusouza1@yahoo.com.br \\
Submetido $09 / 03 / 2017$ - Aceito $27 / 08 / 2017$ \\
DOI: $10.15628 /$ holos.2017.5747 \\
\hline
\end{tabular}

\begin{abstract}
RESUMO
Este artigo analisa a Educação de Jovens e Adultos (EJA) enquanto direito humano, partindo das conquistas nos marcos legais concernentes às juventudes e refletindo, como contraponto, sobre o silenciamento dos sujeitos jovens nessa modalidade de ensino. Trata-se de um recorte da dissertação intitulada $O$ que é ser jovem... aluno... e alagoano: um estudo sobre referências culturais e identidades juvenis, submetida ao Mestrado em Educação Brasileira, do Programa de Pós-Graduação em Educação da Universidade Federal de Alagoas (PPGE/UFAL). A metodologia da pesquisa é qualitativa, mediante análise documental da legislação, como também dos argumentos de três jovens a partir de grupos de discussão e entrevistas semiestruturadas em uma escola pública estadual em Maceió, Alagoas. Como
\end{abstract}

aporte teórico, o artigo apresenta a análise da legislação referente aos jovens e à EJA, como a Constituição Federal, a Lei de Diretrizes e Bases da Educação, o Estatuto da Criança e do Adolescente, o Estatuto da Juventude, dentre outros textos oficiais; bem como conceitos, como de "juventudes", de Pais e Feixa; "condição juvenil", de Abramo, Dayrell e Teixeira; e da relação dos/das jovens com a experiência escolar, de Carrano; Martins, Moreira; Candau, Freire e Sacristán. Identifica-se, nos argumentos analisados, o quanto é urgente que a EJA seja repensada, frente a sua juvenilização, para o reconhecimento dos/das jovens como sujeitos de direitos e um melhor atendimento das reais necessidades dos/as estudantes inseridos/as nessa modalidade de ensino.

PALAVRAS-CHAVE: Juventudes, Educação de Jovens e Adultos, Direitos Humanos.

\section{YOUTH IN YOUTH AND ADULT EDUCATION: CONTRADICTIONS BETWEEN THEIR ACHIEVEMENTS AS SUBJECTS OF RIGHTS AND THE SILENCING IN SCHOOL SPACES}

\begin{abstract}
This article analyzes the brazilian youth and adult education (EJA, in Portuguese) as a human right, based on achievements in the legal frameworks related to youth and reflecting, as a counterpoint, on the silencing of young subjects present in this mode of education. It is a cut of the dissertation entitled What is to be young ... student ... and alagoano: a study on cultural references and youthful identities, submitted to the Master in Brazilian Education, Graduate Program in Education of the University Federal University of Alagoas (PPGE / UFAL). The research methodology is qualitative, through documentary analysis of the legislation, as well as the arguments of three young people from discussion groups and semi-structured interviews in a state public school in Maceió, Alagoas. As a theoretical contribution,
\end{abstract}

the article presents the analysis of the legislation regarding youth and the EJA, such as the Federal Constitution, the Law of Guidelines and Bases of Education, the Statute of the Child and Adolescent, the Statute of Youth, among other official texts; As well as concepts such as "youths", Pais and Feixa; "juvenile condition", by Abramo, Dayrell and Teixeira; And of the relation of the young with the school experience, of Carrano; Martins, Moreira; Candau, Freire and Sacristan. It is identified, in the arguments analyzed, how urgent it is for the EJA to be rethought, in face of its juvenilization, for the recognition of young people as subjects of rights and a better attendance of the real needs of the students inserted in this modality of education.

KEYWORDS: Youth, Youth and Adult Education, Human Rights. 


\section{APRESENTAÇÃO}

No âmbito dos Direitos Humanos, o Estatuto da Juventude (EJ), aprovado em 15 de agosto de 2013, configura-se no marco legal de proteção aos direitos dos/as jovens; segmento da sociedade, tão importante para o futuro, quanto carente de assistência e justiça. Entre os aspectos inerentes às juventudes encontram-se as diversidades, que podem ser compreendidas em vários aspectos: diversidade cultural, de gênero, religiosa, de classe social etc. Trata-se de variações de compatibilidade de valores e símbolos que dão origem às variedades de identidades e, consequentemente, de juventudes, exigindo sensibilidade e critério, para observar em cada jovem as nuances que os/as diferencia e impossibilita que os/as vejamos como uma categoria homogênea. Os textos legais apontam para uma pedagogia multicultural, na qual a bagagem cultural dos sujeitos é considerada, fugindo da imposição da "verdade única", dando lugar à construção do conhecimento partindo da realidade que cerca os indivíduos que aprendem para que possam ampliá-los. Ao refletir sobre o que está posto na legislação e o que observamos na prática das escolas que lidam com as juventudes, percebemos que a efetivação plena dos direitos ainda não é uma realidade.

Este artigo parte de informações obtidas na pesquisa que gerou a dissertação $O$ que é ser jovem... aluno... e alagoano? - um estudo sobre referências culturais e identidades juvenis, realizada no Mestrado em Educação Brasileira, do Centro de Educação da Universidade Federal de Alagoas (CEDU-UFAL). A pesquisa foi realizada em uma escola pública estadual de Maceió, Alagoas, com jovens concluintes do Ensino Médio diurno e noturno (EJA) - utilizando três instrumentos metodológicos: questionário, grupo de discussão e entrevistas individuais. $O$ intuito foi de investigar se esses/as jovens se identificavam em relação à cultura de sua região e de que modo isso acontecia, buscando conhecer que relação se estabelecia entre suas identidades culturais e a experiência escolar no Ensino Médio e qual posição a escola ocupava na construção da identidade cultural desses/as jovens. Para o presente trabalho, nos deteremos especificamente aos relatos de três jovens alunos/as da EJA, baseando-nos nas significativas informações que expressam, procurando refletir sobre os silenciamentos que permeiam a relação desses/as jovens com sua própria condição juvenil e com a escola, em especial, no contexto da EJA.

Iniciaremos introduzindo os marcos legais voltados aos/às jovens e apresentando uma noção sobre os conceitos de juventude, cultura juvenil e condição juvenil. Em seguida, traremos os relatos dos/as jovens entrevistados/as, buscando refletir sobre os mesmos, com base no que os/as autores/as estudados/as dizem sobre os aspectos analisados, o que nos permite identificar evidências que podem sugerir mudanças para o atendimento das necessidades dos/as jovens alunos/as da EJA, considerando as dimensões do coletivo; o respeito às diferenças; a igualdade de oportunidades; a cooperação; a solidariedade; o enfrentamento do preconceito, da discriminação e da violência.

\section{OS MARCOS LEGAIS VOLTADOS AOS/ÀS JOVENS E OS CONCEITOS DE JUVENTUDES}

Na Constituição Federal Brasileira, a categoria "jovem" foi incluída em 2010, através da Emenda Constitucional (EC) $n^{\circ}$ 65, também conhecida como PEC da Juventude - que alterou o capítulo VI do Título VIII da Constituição, para incluir a juventude, ao lado das, já existentes, categorias: família, criança, adolescente e idoso. Até referida emenda, a Constituição Federal 
somente referenciava a juventude no Art. 24, inciso XV - que se limita a prever competência concorrente da União, dos Estados e do Distrito Federal para legislar sobre proteção à infância "e à juventude" - e no parágrafo $4^{\circ}$, do inciso XII, Art. 60, do Ato das Disposições Constitucionais Transitórias, norma inserida pela emenda constitucional $n^{\circ} 53 / 2006$, que faz referência ao aporte de recursos para a educação de "jovens e adultos".

A EC $n^{\circ} 65$ incluiu, no Art. 227, referências à juventude, onde antes somente havia referências a crianças e adolescentes. Destaque-se, em especial, a obrigatoriedade de adoção, pelo Estado, de políticas públicas: de assistência integral à saúde do/da jovem; de integração social do/da jovem portador de deficiência; de garantia do acesso do/da trabalhador/a jovem à escola; de prevenção e atendimento especializado ao/à jovem dependente de entorpecentes e drogas afins.

A Constituição já possuía o capítulo VI do Título VIII, para cuidar da família, da criança, do/da adolescente e do/a idoso/a, embora não definisse com maior precisão, para fins da proteção jurídica especial, quem se enquadraria nessas categorias. Por isso, o Estatuto da Criança e do Adolescente e o Estatuto do Idoso fixam, por lei, a faixa etária na qual se enquadram os segmentos aos quais contemplam. Essa determinação foi feita com uso de critérios razoáveis que levaram em conta estudos científicos da ONU (Organização das Nações Unidas). Assim, criança é "a pessoa até doze anos de idade incompletos" (Art. $2^{\circ}$ do ECA - Lei $n^{\circ}$ 8.609/1990); adolescente é a pessoa "entre doze e dezoito anos de idade" (Art. $2^{\circ}$ do ECA); idoso é a pessoa com idade igual ou superior a 60 (sessenta) anos de idade (Art. $1^{\circ}$ do Estatuto do Idoso - Lei $\mathrm{n}^{\circ}$ 10.741/2003). Alguns dispositivos do ECA, como o parágrafo único do Art. $2^{\circ}$, aplicam-se excepcionalmente às pessoas entre 18 e 21 anos de idade.

Em atendimento ao parágrafo $8^{\circ}$ do Art. 227, incluído pela EC $n^{\circ} 65$, foi aprovado o Estatuto da Juventude (EJ), por meio da Lei 12.852, de 5 de agosto de 2013, a fim de definir com maior precisão os marcos da juventude, para fins de proteção legal específica. $O$ estatuto manteve, em seu Artigo 1으, parágrafo 1으, a faixa etária de 15 a 29 anos, já utilizada anteriormente pela UNESCO, para classificação da pessoa jovem.

O EJ traz em sua Seção I, Artigo 2ํㅡ, oito incisos que apresentam suas premissas:

I - promoção da autonomia e emancipação dos jovens;

II - valorização e promoção da participação social e política, de forma direta e por meio de suas representações;

III - promoção da criatividade e da participação no desenvolvimento do País;

IV - reconhecimento do jovem como sujeito de direitos universais, geracionais e singulares;

V - promoção do bem-estar, da experimentação e do desenvolvimento integral do jovem;

VI - respeito à identidade e à diversidade individual e coletiva da juventude;

VII - promoção da vida segura, da cultura da paz, da solidariedade e da não discriminação; e

VIII - valorização do diálogo e convívio do jovem com as demais gerações.

Dos referidos incisos, especificamente os incisos IV, VI e VIII, se relacionam de modo interessante com as reflexões a que este trabalho se presta, uma vez que se referem ao alinhamento das políticas públicas voltadas aos jovens com as disposições relativas aos direitos humanos em âmbito nacional e internacional; contemplam o respeito às diversidades individuais e coletivas; consideram heterogeneidade das juventudes, ressaltando a proteção aos aspectos 
pessoais e relacionais; e valorizam o diálogo e convívio do/da jovem com as demais gerações, buscando integrá-lo/la no contexto da sociedade da qual faz parte.

O "direito à diversidade e à igualdade" tocante aos/às jovens é registrado na Seção IV, Artigos 17 e 18 do EJ, que ressaltam a importância de políticas de inclusão, de respeito à isonomia e a valorização das diversidades, indispensáveis para a construção de uma sociedade fraterna e pluralista. Neste sentido, o EJ, reforçando uma garantia constitucional, propõe uma ampla proteção contra diversas formas de preconceitos - especialmente os que se referem à origem, etnia, crença, opinião, sexo, orientação sexual e idade - propondo: a elaboração e execução de programas de promoção da igualdade; a capacitação de professores para lidar com situações discriminatórias; inclusão de temas que tratem de preconceito e discriminação no currículo da formação escolar e profissional; proteção das culturas indígenas na elaboração de diretrizes curriculares.

Consideramos o EJ um marco, apesar de tardio, importante na proteção efetiva dos interesses dos/as jovens, porém, como em todas as leis instituídas no Brasil, é preciso diminuir a distância entre o texto oficial e a prática, para que os direitos dos/as jovens sejam plenamente garantidos. Percebe-se que ainda há algumas imprecisões, em alguns termos presentes no documento. Além disso, o texto nem sempre define metas concretas para a eficácia de suas intenções e essa definição é imprescindível para que os objetivos do EJ sejam efetivados de modo eficaz.

Para além dos textos e delimitações oficiais é preciso refletir sobre o/a jovem enquanto sujeito pleno, não somente como uma categoria jurídica. Nesse aspecto, Pais (2003) afirma que é cada vez mais difícil a definição de uma idade a partir da qual um/a jovem se reconhece como adulto, para ele "a juventude aparece cada vez menos associada a uma categoria de idade, e cada vez mais a um conjunto diversificado de modos de vida" (Pais, 2003, p.378). Esse aspecto também é considerado por Feixa $(1999$, p.16), que entende a juventude como a fase da vida individual compreendida entre a puberdade fisiológica (uma condição "natural") e o reconhecimento do status adulto (uma condição "cultural"). Para ele, cada sociedade organiza a passagem da infância para a vida adulta embora as formas e conteúdos dessa passagem são enormemente variáveis (Feixa, 1999, p.18). A juventude tem sido vista como uma condição universal, uma fase do desenvolvimento humano que se encontra em todas as sociedades e momentos históricos.

Pais (2003) discute sobre a necessidade de refletirmos sobre os problemas ditos como específicos dos jovens - citando alguns: os problemas de inserção profissional, de falta de participação social, os problemas de drogas, de delinquência, os problemas com a escola, com os pais - e até que ponto os jovens sentem estes como seus problemas. Segundo o autor é preciso compreender que a juventude é "uma construção social que existe mais como representação do que como realidade" e que antes de assumir o que ele chama de "desafio" que é a "desconstrução (desmistificação) sociológica de alguns aspectos da construção social (ideológica) da juventude, que em forma de mito, nos é dada como uma entidade homogênea" (Pais, 2003, p. 36), faz-se necessário adentrar, ao menos um pouco na construção da noção de culturas juvenis.

Considerando as discussões sobre o tema, as diferentes visões inerentes às correntes sociológicas $^{1}$ que o contemplam, podemos compreender o conceito de cultura juvenil, como

1 Segundo Pais (2003), as correntes teóricas da sociologia da juventude dividem-se em dois principais enfoques: a corrente geracional e a corrente classista. A corrente geracional, define as chamadas culturas juvenis a partir do seu critério etário, ou seja, em relação à "geração adulta", analisando as relações intergeracionais, isto é, à "análise da conservação ou sedimentação (ou não) das formas e conteúdos das relações sociais entre gerações" 
sendo "o sistema de valores socialmente atribuídos à juventude (tomada como conjunto referido a uma fase de vida), isto é, valores a que aderirão jovens de diferentes meios e condições sociais" (Pais, 2003, p. 69), sendo que esses valores podem ser "mais ou menos prevalecentes e diferentemente vividos segundo os meios sociais e as trajetórias de classe em que os jovens se inserem" (ibidem). Assim, as culturas juvenis são vistas sociologicamente como "processos de internalização de normas, como processos de socialização", porém, mesmo sem perder de vista esse preceito, o autor defende que é necessária uma utilização mais dinâmica do conceito de cultura juvenil, em que seja explorado também seu sentido antropológico, que considera os modos de vida específicos e costumes "que expressam significados e valores não apenas ao nível das instituições, mas também ao nível da própria vida quotidiana" (ibidem).

Corroborando com essa premissa, Helena W. Abramo aponta o termo "condição juvenil" ao tratar deste tema. Segundo ela, há duas dimensões presentes nessa condição:

\begin{abstract}
a juventude refere-se ao modo como uma sociedade constitui e atribui significado a esse momento do ciclo da vida, no contexto de uma dimensão histórico-geracional, mas também à sua situação, ou seja, o modo como tal condição é vivida a partir dos diversos recortes referidos às diferenças sociais - classe, gênero, etnia etc. (Abramo, como citado em Dayrell, 2007, p. 1108).
\end{abstract}

Ao voltarmos o olhar para os/as jovens e suas diversas condições juvenis, é inevitável refletir sobre a escola enquanto espaço de convivência e de reafirmação de direitos, enquanto instituição social participante da sociedade local, estadual e nacional. De modo particular, refletiremos aqui sobre a Educação de Jovens e Adultos (EJA), mencionada no Estatuto da Juventude na Seção II, Artigo 7으, parágrafo 2으, que preconiza que "é dever do Estado oferecer aos jovens que não concluíram a educação básica programas na modalidade da educação de jovens e adultos, adaptados às necessidades e especificidades da juventude, inclusive no período noturno, ressalvada a legislação educacional específica". Contraditoriamente, a EJA, mesmo sendo um direito adquirido pelos/as jovens, muitas vezes desconsidera as multiplicidades das juventudes.

\title{
1.1 A Educação de Jovens e Adultos (EJA) como um direito humano tocante ao/a jovem
}

A EJA é uma modalidade da educação básica, no Brasil, destinada às pessoas jovens e adultas que não tiveram acesso ou não concluíram os estudos no Ensino Fundamental e Médio. Consolidou-se em forte relação com o movimento de educação popular, destacando a concepção ampliada de educação de jovens e adultos no sentido de não se limitar apenas à escolarização, mas também reconhecer a educação como direito humano fundamental para a constituição de sujeitos autônomos, críticos e ativos, frente à realidade em que vivem.

O segmento é regulamentado pelo Artigo 370 da Lei no 9.394/1996, conhecida como Lei de Diretrizes e Bases da educação (LDB), que traz, em seu Capítulo II, a Seção V intitulada: Da educação de Jovens e Adultos, que indica que a educação de jovens e adultos deverá ser

(ibidem, p. 55). A corrente classista enfatiza a origem social dos grupos juvenis, tendo, portanto, um enfoque nas diferentes classes sociais em que os grupos juvenis se inserem; "a reprodução social é fundamentalmente vista em termos de reprodução de gênero, de raça, enfim de classes sociais" (ibidem, p.56). O autor propõe analisar as culturas juvenis como os modos de expressões cotitianos dos/as jovens em determinados contextos sociais e históricos, que são atravessadas pelas perspectivas generacionais e de classe. 
destinada àqueles que não tiveram acesso ou continuidade de estudos no ensino fundamental e médio na idade própria - reconhecendo oficialmente a existência de uma parcela da população excluída do direito à educação e propondo a restituição desse direito a todos aqueles que o tiveram negado - determinando ainda, por meio do Parágrafo 1ำ, competências para os Estados e Municípios, num regime de colaboração, sob a assistência da União, responsabilizando-os por assegurarem a gratuidade de oportunidades educacionais adequadas, avaliando as especificidades do público da EJA. A efetividade do referido artigo sugere a obrigação da existência de uma política educacional para a EJA que garanta a universalização do acesso, independentemente da escolarização anterior. É significativo o fato deste mesmo Parágrafo 1으, mencionar a consideração do contexto vivenciado pelo/a educando/a e os conhecimentos e experiências acumulados, o que deveria implicar também no respeito às suas expectativas.

O ECA destina o Capítulo IV à temática educacional. Neste capítulo, o Art. 54, Inciso I, é concernente à EJA apontando que é dever do Estado assegurar à criança e ao adolescente o ensino fundamental, obrigatório e gratuito, inclusive para os que não tiveram acesso ao ensino na idade própria. Neste ponto, consideramos relevante observar a crescente presença de adolescentes nas turmas de EJA, o que requer uma adequação na práxis pedagógica, considerando as especificidades desses sujeitos.

O EJ menciona a EJA na Seção II, Artigo 7으, parágrafo 2으, que diz que "é dever do Estado oferecer aos jovens que não concluíram a educação básica programas na modalidade da educação de jovens e adultos, adaptados às necessidades e especificidades da juventude, inclusive no período noturno, ressalvada a legislação educacional específica". Percebe-se que as especificidades do público jovem são mais uma vez mencionadas.

Outros documentos oficiais também contemplam as especificidades das juventudes, como: a Resolução n. 3, de 15 de junho de 2010, que institui as Diretrizes Operacionais para a Educação de Jovens e Adultos; e a Resolução no 4, de 13 de julho de 2010, que define as Diretrizes Curriculares Nacionais Gerais para a Educação Básica. As duas Resoluções preconizam a utilização de mecanismos específicos para o alunado jovem que considerem suas potencialidades, necessidades, expectativas em relação à vida, às culturas juvenis e ao mundo do trabalho, reforçando a importância do respeito às diferenças entre os sujeitos e a adequação das práticas pedagógicas à multiplicidade identitária observada nas juventudes.

Percebemos que as diversidades e múltiplas identidades inerentes às juventudes são consideradas nos textos dos documentos legais. Porém, na prática pedagógica, é comum observarmos uma educação padronizada, centrada na visão do "sujeito adulto", na qual a dimensão da sociabilidade, apontada por Dayrell (2007) não é observada. É preciso refletir sobre os/as alunos/as jovens enquanto sujeitos "socioculturais", que podem ser conceituados como "seres de sociabilidade e cultura, imprimindo à sua condição natural a marca do humano. Como seres livres, ou melhor, no exercício da liberdade, ultrapassam os comportamentos reativos a fatores internos ou externos, fundando o novo, o inexistente" (Teixeira, 1996, p. 183), porém, no contexto escolar, e especialmente, na EJA é comum que o/a jovem tenha sua condição juvenil anulada e precise abrir mão de suas vivências e se enquadrar na categoria "adulto" de forma brusca, como veremos a seguir nos relatos de estudantes nos quais se baseia este artigo.

\section{CONTRADIÇÕES NA EJA: RELATOS SOBRE SILENCIAMENTOS DAS JUVENTUDES}

Ao lidar com o público jovem - bem como qualquer segmento da sociedade - é imprescindível a compreensão das diferenças e o respeito às diversidades; compreender os 
sujeitos enquanto indivíduos que possuem uma historicidade, com visões de mundo, escalas de valores, sentimentos, emoções, desejos e projetos, com lógicas de comportamentos e hábitos que lhe são próprios (Dayrell, 1996, p. 140). Essa outra perspectiva implica em superar a visão homogeneizante e estereotipada da noção de aluno, dando-Ihe outro significado.

Nas falas dos/as três jovens entrevistados/as perceberemos uma amostra de como algumas situações vividas nas salas de aula da EJA podem ser marcantes na experiência escolar de jovens alunos/as desse segmento. Dialogando com os autores que se debruçam sobre essa temática, poderemos refletir sobre esse contexto complexo, partindo do ponto de vista de quem nem sempre é ouvido, de quem mais precisa se expressar.

Vinícius $^{2}, 19$ anos, sexo masculino, solteiro, negro, filho adotivo. Trabalhava num supermercado e dizia gostar de jogar futebol. Pretendia cursar faculdade de Administração. Desde que sua mãe faleceu, ele passou a viver só com o pai, alcoólatra, em uma das regiões mais pobres dos arredores da escola. Muito agitado e falante, Vinícius se destacou, no momento da pesquisa, por seus posicionamentos seguros, que revelavam um alto nível de esclarecimento em comparação aos demais, demonstrando muita inteligência e coerência em suas falas. Porém, para a Diretora da escola, Vinicius era "o polêmico", um "aluno-problema".

Arnaldo $^{3}, 20$ anos, sexo masculino, branco, solteiro, morava com a mãe; evangélico e cantor de Rap; muito engajado no movimento Hip-Hop; é muito crítico, se posicionando firmemente sobre tudo. Também tido como "polêmico" pelos professores, persistia em comparecer às aulas, mesmo se sentindo deslocado na escola. Já foi usuário de drogas e se envolveu com o tráfico, mas passou a utilizar o Rap para conscientizar outros jovens. Sua atuação nesse movimento cultural forneceu a este jovem uma segurança e uma consciência de sua identidade juvenil que se sobrepõe à experiência escolar. Arnaldo buscou no Hip-Hop as respostas que a escola não the deu. Nas ações realizadas por este movimento ele encontra o espaço para questionar e se expressar e sente falta desse espaço na escola.

$\mathrm{Val}^{4}, 24$ anos, se travesti, solteira, branca, morava com os pais, trabalhava como cabeleireira e gostava de cantar. Em seu relato, Val demonstrou sentir falta do apoio dos professores no sentido de contribuir para a disseminação de informações referentes à cultura na qual está inserida. Assim como Arnaldo, Val também possuía atividades extraescolares, atuando no movimento $\mathrm{GLBT}^{5}$. A jovem fazia questão de utilizar seu "nome social" 6 e já havia passado por diversas situações de preconceito devido à sua sexualidade. Segundo ela, a maior rejeição parte dos professores. Durante a entrevista, a jovem manifestou a percepção de que há algo a ser feito:

\begin{abstract}
Uma professora, umas três semanas seguidas, me chamou pelo meu nome de registro e eu já tinha pedido pra ela me chamar pelo meu nome social. Mas ela insistiu em me chamar pelo nome de registro na chamada. Então eu faria mais projetos pra ensinar os professores... porque os alunos se enturmam mais fácil. Mas os professores precisam ser mais conscientizados. Porque é assim, todo mundo tem seus direitos só que, como você é considerada "normal" pra sociedade você recebe seus direitos. E eu, pra receber os meus, tenho que lutar. (Val, 24 anos, estudante da EJA).
\end{abstract}

$2 \quad$ Nome fictício.

$3 \quad$ Nome fictício.

$4 \quad$ Nome fictício.

5 LGBT (Lésbicas, Gays, Bissexuais, Travestis, Transexuais e Transgêneros): sigla utilizada para denominar o movimento político-social e as culturas desses grupos identitários.

$6 \quad$ Entende-se por nome social aquele pelo qual travestis, transexuais e transgêneros se identificam e são identificados pela sociedade. Fonte: Portaria 233, de 18/05/2010, Ministério do Planejamento, Orçamento e Gestão. Art. 1, Parágrafo Único. 
Para Moreira \& Candau (2003, p. 159), "a escola é, sem dúvida, uma instituição cultural". Ela é um ambiente rico de experiências e entrelaçamentos de culturas. É importante refletirmos sobre o que deveria ser uma das mais importantes tarefas das instituições escolares hoje: contribuir para que os/as jovens possam realizar escolhas conscientes sobre suas trajetórias pessoais e constituam os seus próprios acervos de valores e conhecimentos que já não mais são impostos como heranças familiares ou institucionais (Carrano \& Martins, 2011, p. 45). Porém observa-se que a escola tem assumido uma posição oposta, de acordo com Sposito:

\begin{abstract}
a escola conta com mecanismos de silenciamento que promovem a invisibilidade das práticas que não se encaixam nos cotidianos escolares institucionalizados e pouco abertos para as expressividades das culturas juvenis. Nesse contexto, o jovem é homogeneizado na condição de aluno que necessita responder positivamente aos padrões do "ser estudante" que a instituição almeja. (Sposito, como citado em Carrano \& Martins, 2011, p. 45)
\end{abstract}

Os/as jovens são pressionados/as a atender as expectativas da escola, enquanto suas próprias expectativas pessoais nem sempre são consideradas. Para Sacristán (2005), a sociedade influencia e de certo modo pretende condicionar os indivíduos numa determinada nova forma de viver, e por isso, as práticas pedagógicas, geralmente são pautadas em currículos homogêneos que buscam contemplar as necessidades de todos, sem diferenciação, sem olhar para cada um em sua individualidade. Para o autor, a escola nasceu e até hoje mantêm em suas raízes a função de normalizar os corpos na sociedade, ou seja, tem a função de manter a sociedade como ela se encontra, ou ajudar a modificá-la quando ela requerer essa atitude.

Percebemos essa imposição de forma ainda mais marcante em algumas salas de aula da Educação de Jovens e Adultos - EJA. Nesse ambiente, os/as alunos/as- adultos, jovens e até adolescentes - têm suas identidades homogeneizadas em um único perfil de "aluno fora de faixa", automaticamente empurrados para a categoria de "aluno adulto", tendo suas juventudes silenciadas. As questões que envolvem os choques de gerações que se apresentam na EJA, carecem de muitas reflexões e estudos com o intuito de tentar apontar ações que solucionem ou, ao menos, amenizem as inquietações que trazem prejuízos à vida escolar do público a que se destina esse segmento da educação.

Ao ser questionado sobre que mudanças faria na escola onde estuda para torná-la melhor, um dos jovens entrevistados apontou que a relação de contraste entre as realidades dos horários da manhã e da noite pode se apresentar de uma forma praticamente traumática para alguns jovens.

\footnotetext{
Se eu não estivesse trabalhando, eu não vinha pra noite! Tem muita gente que vem pra noite por causa do ensino que é fraco, porque quer passar. Mas eu sinto falta. Às vezes quando eu estou de folga eu venho aqui de manhã. Pra ver o povo, pra estar... com o grupo... Você está na sala, tem aquele "êêêêê!!" que começa lá atrás e todo mundo faz, aí o professor olha e diz: "O que é isso?" Aqui eu se eu puxar isso, quem vai fazer? Ninguém vai fazer! Como eu falo muito e brinco muito, sempre que eu tirava uma "resenha" todo mundo ria! Hoje, se eu falar, todo mundo olha pra mim e diz: "Psiu! Vamo estudar!" (Vinícius, 19 anos, estudante da EJA).
}

Vinícius fala de momentos que constituem as melhores lembranças da experiência escolar, aquelas que todos os que passam por essa experiência carregam para sempre; os momentos lúdicos, até mesmo de leves transgressões, que são inerentes à juventude e que os/as jovens que passam a estudar nos cursos noturnos, deixam de experimentar, quando são 
inseridos/as numa sala composta por faixas etárias diversas, quando não se sentem reconhecidos/as nesse espaço. É fundamental considerar a "dimensão do encontro" tratada por Dayrell (1996, p.148), ou seja, a escola como espaço privilegiado para a sociabilidade juvenil.

Os danos causados pela aplicação de uma visão homogeneizante na EJA têm destinatários certos: os/as jovens, que por necessitarem trabalhar, ou por estarem fora da faixa etária prevista para as turmas do ensino considerado "regular", são inseridos na EJA. Esses/as jovens se depararam com uma turma composta por sujeitos de diversas idades, vindos de realidades diversas, com diversas trajetórias escolares, como por exemplo: sujeitos recém-alfabetizados que estão em um nível de conteúdos aquém do conhecimento que os/as jovens que cursaram o ensino "regular" recentemente; ou sujeitos que estão há décadas fora da escola e estão retomando os estudos aos 50 anos de idade. São realidades culturais diferentes e que poderiam ser tratadas pedagogicamente de formas diferentes, onde se pudessem atender às especificidades e também criassem pontos de encontro para que a diversidade deixasse de ser um problema e passasse a ser uma fonte de riqueza para as aprendizagens. Porém, aparentemente, o sistema educacional ignora essa necessidade e insiste em tratar os/as alunos, especialmente os da EJA, como uma categoria homogênea.

Não obstante o pensamento de Freire, que pregava uma educação livre das amarras da formalidade, e ciente do que indica Gadotti quando diz que "crianças, jovens e adultos podem aprender juntos muitas coisas. A idade não é o único critério para organizar as aprendizagens. Todos aprendem juntos, "mediados pelo mundo", dizia Paulo Freire." (Gadotti, 2013, p. 26), percebemos que essa visão se aplica a uma educação informal, dialógica e construcionista, o que, convenhamos, não se aplica à maioria das escolas inseridas no ensino formal, público e urbano, no Brasil, onde o que vemos são salas de aula em que a idade é utilizada como critério, não somente para forçar aprovações de alunos/as sem condições de serem aprovados/as, como para forçar alunos/as "fora da faixa etária" a migrarem para a EJA onde passam a ser tratados/as como "adultos".

Vale remarcar que também os/as pessoas adultas precisam se expressar em suas diversidades e ter seus diretos respeitados e isso requer repensar as práticas pedagógicas e o espaço escolar. Porém, nesse artigo nosso foco são as juventudes inseridas na EJA. Nesse sentido concordamos com Carrano quando afirma que "a invisibilidade imputada pela escola aos jovens ao traduzi-los apenas à condição de alunos contribui para adjetivá-los negativamente sempre que expressem suas identidades através de marcadores culturais próprios desse período da vida" (Carrano \& Martins, 2011, p. 53). Os jovens passam ser, ainda mais do que antes, considerados somente como alunos, a sua condição de jovem é ainda mais ignorada, até mesmo censurada, nessa nova realidade.

\footnotetext{
O que eu mudaria se pudesse era isso: tem jovens numa mesma turma, que estudam a noite pelo fato de trabalharem... e pegava aquela turma mais velha e fazia turmas diferentes. Pela faixa etária... fazia aquela turma de jovens pra pegar mais pressão e pegava aquela turma que tá há muito tempo sem estudar e ensinava de uma forma diferente, porque junto é muito difícil! A gente quer algo mais! É outro ritmo! (Vinícius, 19 anos, estudante da EJA).
}

A visão desse jovem de 19 anos, sobre a realidade do ensino noturno, pode despertar diversars reflexões quanto à dissonância, entre as práticas pedagógicas e as reais necessidades de alguns dos jovens inseridos na EJA. 
Os/as jovens entrevistados/as expressaram um sentimento de frustração diante da percepção de que, no sistema educacional público, o conhecimento do/a aluno/a não está em primeiro lugar. "É pelo certificado mesmo. Porque aprender a gente não tá aprendendo nada! Porque a gente tem aula dois dias na semana, aula não! Tem um texto, trabalhinho e pronto!" (Val, 24 anos, estudante da EJA). Percebemos que os/as jovens têm a impressão de que sua educação é tratada de forma meramente quantitativa: "A preocupação dos professores que eu vejo, de alguns, e da escola, não é ensinar ao aluno, é fechar caderneta! Quem aprendeu, aprendeu... quem não aprendeu..." (Vinícius, 19 anos, estudante da EJA); "Todos os jovens daqui têm oportunidade de estudar, mas cadê a educação? Já tá tendo matrícula para o ano que vem aqui na escola. Mas a educação não anda!" (Arnaldo, 20 anos, estudante da EJA). Consideramos que a má qualidade da educação fornecida às crianças, jovens e adultos constitui uma clara negação de um direito humano primordial: o direito à educação.

Nesse aspecto, Dayrell afirma que "a relação dos jovens pobres com a escola expressa uma nova forma de desigualdade social, que implica o esgotamento das possibilidades de mobilidade social para grandes parcelas da população e novas formas de dominação" (Dayrell, 2007, p. 1122). O sistema público educacional fornece um serviço cuja qualidade não proporciona uma igualdade de condições aos/às jovens que o frequentam, se compararmos com a realidade de jovens que frequentam o sistema privado de ensino, que raramente frequentarão as salas de aula da EJA. Trata-se de um sistema que sofre com a falta de professores e com o atrelamento às metas estabelecidas pelo Governo Federal. As consequências disso se revelam nas salas de aula, onde os/as docentes chegam à escola na metade do ano letivo para assumir disciplinas que antes estavam sem professor, tendo que cumprir o calendário e concluir as avaliações no mesmo prazo das disciplinas que estavam sendo lecionadas desde o início do ano letivo. Os/as professores fazem o que podem para se adequar ao sistema, porém, além dos prejuízos no conteúdo das disciplinas, ao qual os/as estudantes deveriam ter acesso, todos esses fatores geram o descontentamento dos/as docentes e dos/as jovens alunos/as.

\section{CONSIDERAÇÕES FINAIS}

Verifica-se, de várias formas, no contexto atual, o empenho em analisar, classificar este jovem e apontá-lo como o caminho, o futuro da sociedade. Ao mesmo tempo, os jovens vêm sendo constantemente convocados a ter atitude ou convidados a consumir produtos que os enquadram em determinados grupos ou "tribos". A expressão "ter atitude" é cada vez mais relacionada às características desejáveis ou pertencentes ao universo jovem.

A escola poderia ser um local onde as experiências ali vividas fizessem parte do projeto de vida dos/as jovens que passam por ela. Concordamos com Krawczyk (2003), quando afirma que é preciso conhecer melhor o universo dos/as alunos/as do noturno visando elaborar uma proposta de trabalho que responda às especificidades desses sujeitos; dando atenção ao "sujeito "jovem aluno", não como uma categoria "sem endereço", mas, ao contrário, na sua materialidade" (Krawczyk, 2003, p.195); considerando também o imaginário social dos/as docentes e a importância da influência desse imaginário no relacionamento de professores/as e alunos/as e na organização do trabalho pedagógico.

As reflexões aqui apresentadas ressaltam a importância de uma Educação que articule ações político-sociais, com o intuito de fomentar no ambiente escolar o respeito às diferenças, à igualdade de oportunidades, à cooperação, à solidariedade e ao enfrentamento a todo o tipo de violência, preconceito e discriminação. Consiste em formar os/as profissionais da Educação para 
que enxerguem o/a aluno/a jovem da EJA como, antes de tudo "jovem", e não como apenas como uma categoria "aluno", como se esta fosse homogênea, sem considerar suas diversidades e múltiplas constituições identitárias.

A EJA configura-se como uma grande conquista no âmbito dos Direitos Humanos, já que se volta aos/às cidadãos/dãs que não tiveram acesso à educação na faixa etária correta. Porém, por muito tempo a EJA esteve configurada quase que exclusivamente como Educação de Adultos e, com o rejuvenescimento do seu público, faz-se necessário que a EJA reconfigure seu campo de prática e análise, considerando os novos perfis e o novo contexto histórico dos/as alunos/as jovens. Além disso, as necessidades, as potencialidades para ampliar seus conhecimentos, as expectativas em relação à vida desse público precisam ser consideradas para que se efetive o atendimento pleno de todos os sujeitos que necessitam ter plenamente efetivado seu direito à educação.

\section{REFERÊNCIAS}

Abramo, H. W. (2005) Condição Juvenil no Brasil Contemporâneo. In Abramo, H. W. \& Branco, P. P. M. (Orgs.). Retratos da Juventude Brasileira: análises de uma pesquisa nacional. (pp. 37-72). São Paulo: Instituto Cidadania/Fundação Perseu Abramo.

Lei no 12.852, de 5 de agosto de 2013 (2013). Institui o Estatuto da Juventude e dispõe sobre os direitos dos jovens, os princípios e diretrizes das políticas públicas de juventude e o Sistema Nacional de Juventude - SINAJUVE. Brasília, DF. Recuperado em 08 de março 2017, de http://www.planalto.gov.br/ccivil_03/_ato2011-2014/2013/lei//12852.htm

Resolução no 3, de 15 de junho de 2010 (2010). Institui Diretrizes Operacionais para a Educação de Jovens e Adultos nos aspectos relativos à duração dos cursos e idade mínima para ingresso nos cursos de EJA; idade mínima e certificação nos exames de EJA; e Educação de Jovens e Adultos desenvolvida por meio da Educação a Distância. Brasília/DF. Recuperado em 08 de março 2017, de

http://confinteabrasilmais6.mec.gov.br/images/documentos/resolucao032010cne.pdf

Resolução no 4, de 13 de julho de 2010 (2010). Define Diretrizes Curriculares Nacionais Gerais para a Educação Básica. Brasília, DF. Recuperado em 08 de março 2017, de http://portal.mec.gov.br/dmdocuments/rceb004_10.pdf

Carrano, P. C. \& Martins, C. H. (2011). A escola diante das culturas juvenis: reconhecer para dialogar. Educação. 36(1) 43-56. Recuperado em 08 de abril, 2016, de https://periodicos.ufsm.br/reveducacao/article/view/2910

Dayrell, J. (1996). A escola como espaço sócio-cultural. In Dayrell, J. (Org.). Múltiplos olhares sobre educação e cultura. (pp. 136-178). Belo Horizonte, MG: UFMG.

Dayrell, J. (2007). A escola faz as juventudes? Reflexões em torno da socialização juvenil. Educação de Sociedade, 28(100) 1105-1128. Recuperado em 08 de abril, 2016, de http://www.scielo.br/scielo.php?pid=S0101-

$73302007000300022 \&$ script=sci_abstract\&tIng=pt

Feixa, C. (1999) De jóvenes, bandas y tribus: antropologia de la juventud. Barcelona: Ariel.

Gadotti, M. (2013). Educação de Adultos como Direito Humano. EJA em debate (2)12-29. Recuperado em 22 de dezembro, 2015, de https://periodicos.ifsc.edu.br/index.php/EJA/article/download/1004/pdf

Krawczyk, N. R. (2003). A escola média: um espaço sem consenso. Cadernos de Pesquisa (120) 169-202, Recuperado em 08 de março, 2017, de 
http://www.scielo.br/pdf/cp/n120/a10n120.pdf

Moreira, A. F. \& Candau, V. M. (2003). Educação escolar e cultura(s): construindo caminhos. Revista Brasileira de Educação (23)156-168. Recuperado em 25 de janeiro, 2016, de http://www.scielo.br/scielo.php?pid=S1413-

24782003000200012\&script=sci_abstract\&tlng=pt

Pais, J. M. (2003). Culturas juvenis (2a. ed.) Lisboa: INCM.

Sacristán, J. G. (2005). O aluno como invenção. Porto Alegre: Artmed.

Teixeira, I. (1996). Os professores como sujeitos sócio-culturais. In Dayrell, J. (Org.). Múltiplos olhares sobre educação e cultura (pp. 179-194). Belo Horizonte: UFMG. 